\title{
Workshop on
}

\section{'Molecular biological techniques in nutritional science'}

\author{
Chairmen's introduction \\ BY PAUL TRAYHURN AND JOHN K. CHESTERS \\ Division of Biochemical Sciences, Rowett Research Institute, \\ Bucksburn, Aberdeen AB2 9SB
}

Molecular biology is generally considered to be the most important development in the sciences during the latter half of the twentieth century. The concepts and technology spawned by molecular biology have permeated deeply into many areas of the biological sciences, from medicine to ecology. There is, however, a distinct perception that the impact on nutritional science has been rather limited, certainly in relation to the potential, and this is particularly so in the UK. There may be a number of reasons for the restricted interest in molecular biology by the nutritional sciences community. A key barrier, however, is the belief that the area is difficult to access for those outside, the vocabulary alone being difficult to penetrate.

The aim of the present Workshop was to inform the nutritional sciences community in the UK, through the Nutrition Society, of the opportunities and challenges presented by molecular biology. A series of presentations, representing a teach-in of key techniques and procedures, was given. Each paper addressed the following issues:

What is the principle of the technique?

How is it carried out?

What nutritional questions can be addressed by a particular technique?

The emphasis was, wherever possible, on simplicity and accessibility. The concepts and principles behind the following key procedures in molecular biology were described: Gene cloning, Northern blotting, Southern blotting, Polymerase chain reaction, DNA sequencing, and Transgenics.

We hope that the printed versions of the presentations will be of value in encouraging nutritional scientists to grasp the opportunities available from the harnessing of molecular biology. 